\author{
Ozgur Turk ${ }^{1 \star}$, Hasan Polat ${ }^{1}$ and Bartu \\ Badak $^{2}$ \\ ${ }^{1}$ Sivrihisar State Hospital, General Surgery \\ Department, Eskisehir, Turkey \\ ${ }^{2}$ Banaz State Hospital, General Surgery Department, \\ Eskişehir, Turkey \\ Dates: Received: 27 October, 2015; Accepted: 17 \\ November, 2015; Published: 19 November, 2015 \\ *Corresponding author: Ozgur Turk, Sivrihisar \\ State Hospital, General Surgery Department 26040 \\ Eskisehir, Turkey, Tel: +905054403377; Fax: \\ +902227112002; E-mail: drozgurturk@gmail.com \\ www.peertechz.com \\ ISSN: 2454-2968 \\ Keywords: Hydatid cyst; Liver; Echinococcus
}

\section{Case Report \\ Primary Multiple Giant Hydatid Cyst of the Liver: A Case Report}

\section{Introduction}

Hydatid cyst is a parasitic infection of liver. One of the most frequent reason of the liver mass is hydatid cyst in tropical and rural countries. Infection of Echinococcus granulosus larvae lied behind of this disease. The most effected organ is liver (75\%) and lung (15\%) [1]. Other rare seen anatomical locations are brain, breast, heart, spleen, bone, spleen, abdominal wall. Clinical symptoms are varied according to the size, anatomic location and stage of hydatid cyst. The course of the disease can be silent in most patients until a complication occurs or raise the size of cyst a huge amount [2]. In some cases rapidly grow up of cyst mimic liver masses. Composition of clinical history, family history, physical examination, serological and immunological studies direct definitive diagnosis. The most used diagnostic method for differential diagnosis is abdominal ultrasound (USG). Abdominal tomography (CT) or magnetic resonance imaging (MRI) are used for advanced diagnosis. There are lots of techniques can be used for treatment such as medical treatment, percutaneous aspiration and surgical removal of cyst [3]. Here, we want to report a primary multiple giant hydatid cyst of liver widespread in right and left lobe. This case is interesting because of the plenty of the cysts and dimensions.

\section{Case Presentation}

A sixty years old female admitted our hospital with abdominal pain. She had not any surgical history. Family history of the patient was unremarkable. On physical examination, a rigid and tense abdominal mass was palpable filling upper abdomen. In laboratory studies, there was no hematological abnormality; biochemistry results were unremarkable. Anti-Echinococcus antibodies were not evaluated. Brucella agglutination test was positive. Abdominal ultrasound showed $74 \times 75 \mathrm{~mm}$ in segment two, $115 \times 91 \mathrm{~mm}$ in segment six and $115 \times 62 \mathrm{~mm}$ in segment four type four hydatid cysts (Figure 1). Abdominal tomography performed for differential diagnosis and result: increased liver size and 96x56 mm measured cyst in segment four; 90x97 mm measured cyst in segment six and seven; 73x64 mm measured cyst in segment two and three (Figure 2). Patient was evaluated for PAIR treatment but because of the multiple location and dimensions of the cysts patient was admitted for surgery. During surgical exploration; there was three giant hydatid cyst filling both right and left lobe of the liver. Falciform ligament ligated and liver normalized. Hypertonic 3\% $\mathrm{NaCl}$ solution injected into the cyst that at the left lobe of the liver. After fifteen minutes cyst aspirated and pericystectomy was performed by with a Harmonic scalpel

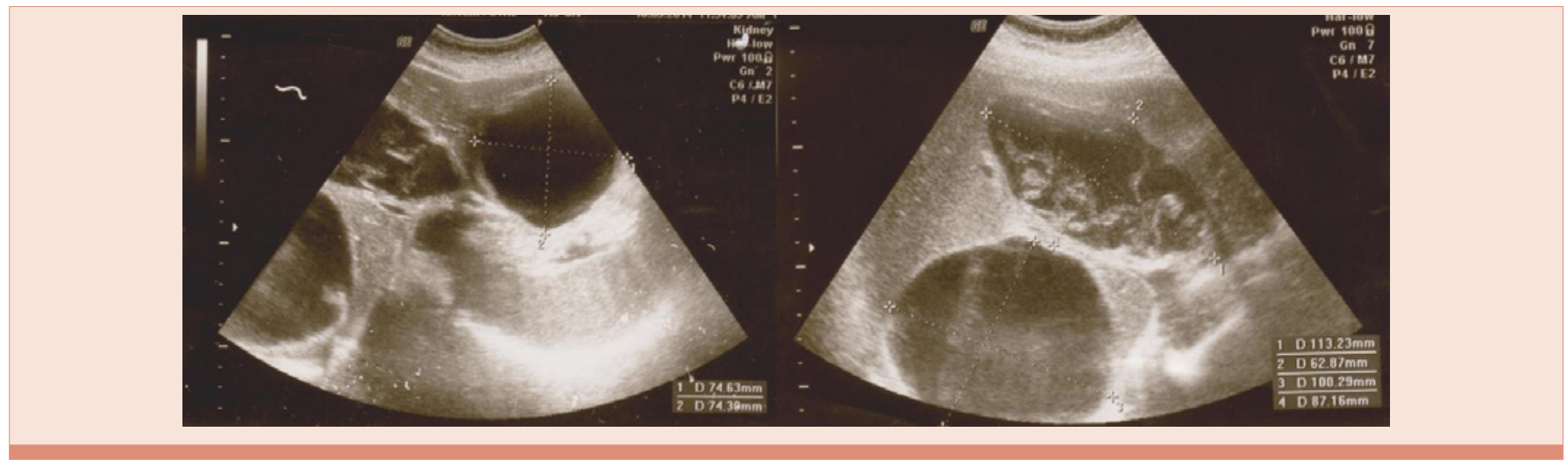

Figure 1: Abdominal ultrasound showed $74 \times 75 \mathrm{~mm}$ in segment two, $115 \times 91 \mathrm{~mm}$ in segment six and $115 \times 62 \mathrm{~mm}$ in segment four type four hydatid cysts. 


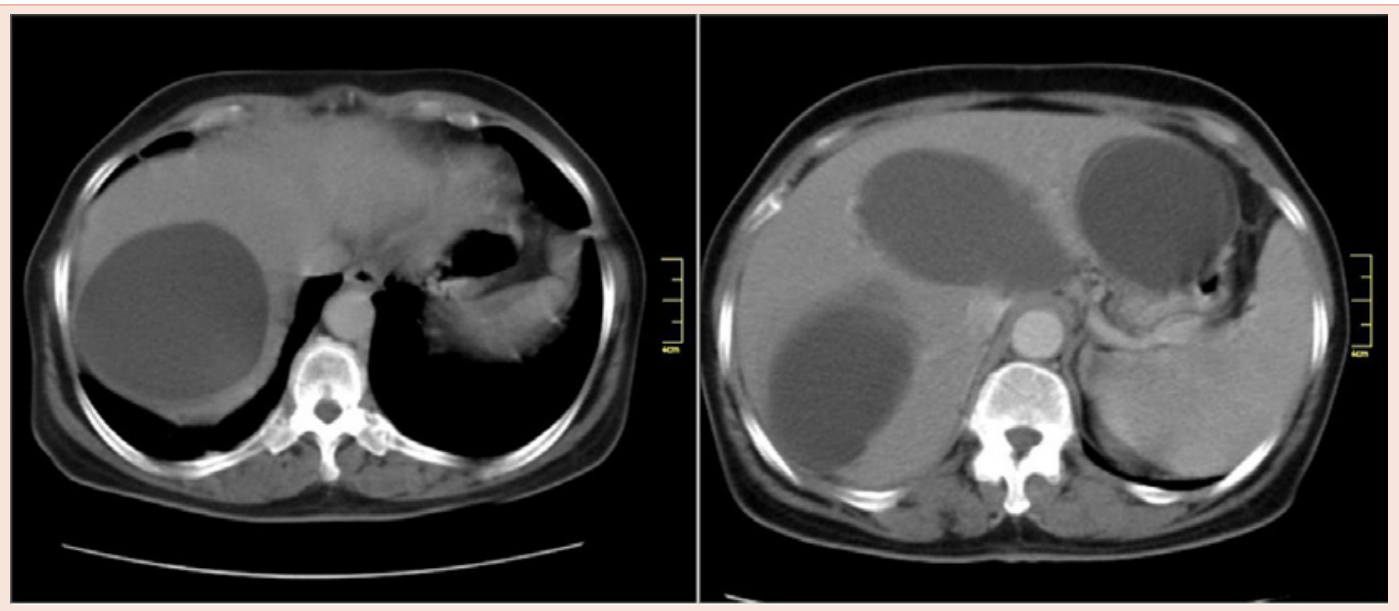

Figure 2: Computerized tomography study: increased liver size and 96x56 mm measured cyst in segment four; 90x97 mm measured cyst in segment six and seven; $73 \times 64 \mathrm{~mm}$ measured cyst in segment two and three.

(Ethicon Endo-Surgery, Inc., Cincinnati, Ohio) until the border of healthy liver parenchyma. There was no bleeding from the liver. Same surgical procedure performed for another two cysts. There was a biliary fistula in the residual cyst cavity in segment four and two. Biliary fistulas primarily sutured. After pericystectomy omentum was packed into residual cavity and fixed. Drains placed in sub hepatic, sub diaphragmatic area. Postoperative period was uneventful. Drains removed four days after surgery. Patient was discharged nine days after surgery with the Albendazole treatment. During at 6 months follow up of patient there was no problem and no recurrence of hydatid cyst.

\section{Discussion}

As well-known echinococcosis is anthropozoonosis affects human beings. Dog is the definitive host; human is the accidental intermediate host. Embryonic eggs reach the liver through the digestive system. Sometimes eggs go too far from the hepatic veins [4]. First caesura is generally lung, but rarely eggs can reach any other tissue of the body. Small hydatid cysts do not cause any symptoms. When it reaches the bigger amount patient became symptomatic. Most common symptom is abdominal pain. Fever can occur if the cyst is infected. The major complication of hydatid cyst is rupture. The cyst can be ruptured into peritoneal cavity, thoracic cavity or biliary duct. Infection, adjacent organ invasion, cholangitis, obstructive jaundice, anaphylactic shock can be listed as other complications [5]. USG, CT and MRI used in the diagnosis of hydatid cyst. USG is the most reachable and often used diagnostic method. In our case we performed USG at the time of admission to hospital. Diagnosis is confirmed by CT that has guided to the surgical procedure and gave us hints about complications. In this case CT showed us hepatic vascular and biliary structures were normal. Hydatid cysts are classified according to the classification of Hussein and Gharbi: Type I: pure liquid Collection, Type II: liquid collection in divided into halves wall, Type III: liquid collection divided up with girl's vesicles, Type IV: formation with heterogeneous echo structure, Type V: formation with calcified wall [6]. In our case cysts were classified as type IV in USG. MRI has a definitive importance in diagnosis and anatomical relations of hydatid cysts. Ideal treatment method must include complete elimination of parasite from organism and prevent recurrence of disease [7]. Treatment method must be chose considering stage of cyst, localization, size and existence of complications. Nonoperative techniques like percutaneous drainage and drug therapy chose in small sized cysts and patients who don't want to undergo surgery. Surgical techniques include cystectomy, pericystectomy, hepatectomy, omentoplasty and capitonnage. Surgical treatment has the most potential of removing cyst completely and low recurrence rate [8]. In multiple cysts surgical management is sometimes difficult. It is better to drain all the cysts at the same time. In unreachable cysts and poor conditioned patients two stage treatment can be chose. [9] In conclusion, giant hydatid cysts can cause complications such as rupture and anaphylactic shock. Surgical interventions can prevent complications and spread of Echinococcus also gives a chance of curative treatment.

\section{References}

1. Turgut AT, Altin L, Topçu S, Kiliçoğlu B, Aliinok T, Kaptanoğlu E, Karademir A, et al. (2007) Unusual imaging characteristics of complicated hydatid disease. Eur J Radiol. 63: 84-93.

2. Ozturk G, Aydinli B, Yildirgan MI, Basoglu M, Atamanalp SS, et al. (2007) Posttraumatic free intraperitoneal rupture of liver cystic echinococcosis: a case series and review of literature. Am J Surg 194: 313-316.

3. Agaoglu N, Turkyilmaz S, Arslan MK (2003) surgical treatment of hydatid cysts of the liver. Br J Surg 90:1536-1541.

4. M. Moujahid, I. Enna-Faa, M. Ghari, I. Raissouni and M. Hassan Tahiri, et al. (2014) Giant Hydatid Cyst of the Liver: A Case Report. Int J Clin Med 5:1-3.

5. Chautems R, Bühler LH, Gold B, Giostra E, Poletti P, et al. (2005) Surgical management and long-term outcome of complicated liver hydatid cysts caused by Echinococcus granulosus. Surgery 137: 312-316

6. H. G. Schipper and P. A. Kager, (2004) Diagnosis and Treatment of Hepatic Echinococcosis: An Overview. Scand J Gastroenterol 241: 50-5.

7. Craig PS, McManus DP, Lightowlers MW, Chabalgoity JA, Garcia HH, et al. 
Turk et al. (2015)

(2007) Prevention and control of cystic echinococcosis. Lancet Infect Dis 7 385-394.

8. Mustafa M I T, Abbas M, Khan A A, Mustafa R I T, et al. (2011) Hydatid Cyst of Liver: A Case Report. Pakistan journal of medical and health sciences
5:803-805.

9. Prousalidis J, Kosmidis $\mathrm{CH}$, Fahantidis E, Harlaftis N, Aletras O, et al. (2004) Surgical treatment of multiple cystic echinococcosis. HPB (Oxford) 6:110 114.

Copyright: (c) 2015 Turk O, et al. This is an open-access article distributed under the terms of the Creative Commons Attribution License, which permits unrestricted use, distribution, and reproduction in any medium, provided the original author and source are credited. 